\section{Anomalous origin of the left main coronary artery from the right coronary sinus}

A 62-year-old gentleman was referred for coronary surgical revascularisation due to increasing symptoms of angina pectoris. Preoperative coronary angiography showed the left main coronary artery (LMCA) arising adjacent to the right coronary from the right coronary sinus (figure 1). The left anterior descending artery coursed at $90^{\circ} \mathrm{s}$ to the LMCA with the circumflex artery a continuation of the LMCA. Obtuse marginal branches of the circumflex are also visible. There was surgically graftable three vessel disease with preserved left ventricular function. The patient had coronary artery bypass grafting performed.

Intraoperatively, the LMCA was noted traversing the anterior aspect of the right ventricular outflow tract giving rise to the left anterior descending and circumflex arteries as suggested on the angiogram (figure 2). Postoperative course was uneventful with discharge home on the sixth postoperative day.

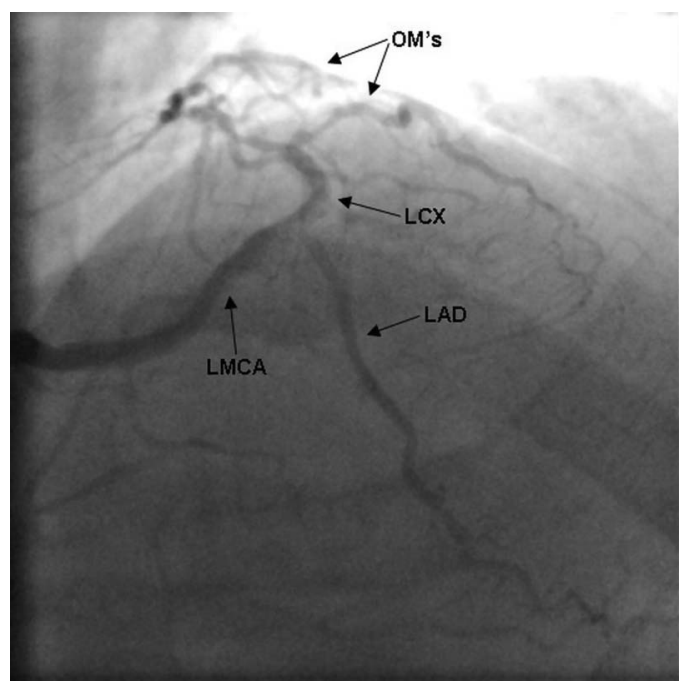

Figure 1 Coronary angiography showing the left main coronary artery (LMCA) arising adjacent to the right coronary artery, from the right coronary sinus, with the left anterior descending artery coursing at $90^{\circ} \mathrm{S}$ to the LMCA with the circumflex artery a continuation of the LMCA. Obtuse marginal branches of the circumflex are also visible.

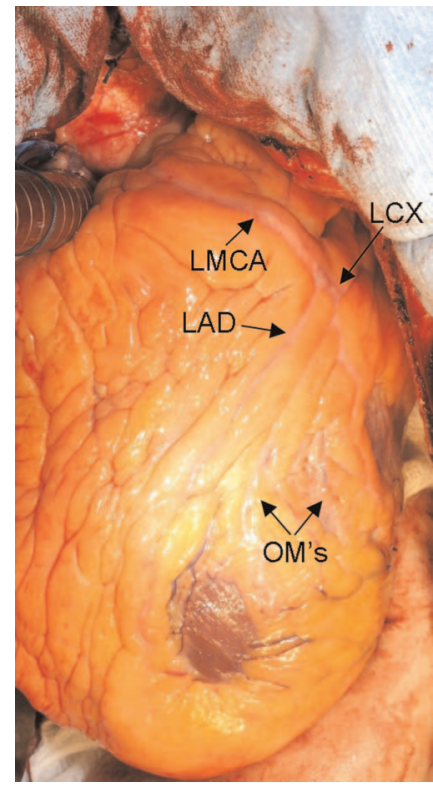

Figure 2 Intraoperative appearance of the left main coronary artery (LMCA) traversing the anterior aspect of the right ventricular outflow tract giving rise to the left anterior descending (LAD) and circumflex arteries.

This is a described coronary anomaly but is exceedingly rare. A series of 126595 patients having coronary angiography noted origin of LMCA from the right coronary sinus in a total of only $22(0.017 \%)$ with this 'anterior' course the least common of five subtypes. ${ }^{1}$

\section{Ian Paul, Harry Parissis}

Department of Cardiothoracic Surgery, Royal Victoria Hospital, Belfast, UK

Correspondence to Dr lan Paul, Department of Cardiothoracic Surgery, Royal Victoria Hospital, Grosvenor Road, Belfast BT12 6BA, UK; ian.paul@talk21.com

Contributors Both listed authors have been involved in the conception, drafting and final approval of the manuscript.

Competing interests None.

Patient consent Obtained.

Provenance and peer review Not commissioned; internally peer reviewed.

To cite Paul I, Parissis H. Heart Asia Published Online First: [please include Day Month Year] doi:10.1136/heartasia-2013-010347

Heart Asia 2013;0:99. doi:10.1136/heartasia-2013-010347

\section{REFERENCE}

1 Yamanaka O, Hobbs RE. Coronary artery anomalies in 126,595 patients undergoing coronary arteriography. Cathet Cardiovasc Diagn 1990;21:28-40. 